\title{
EDITORIAL
}

\section{One Year of Sustainable Development Research}

\author{
Marc A. Rosen ${ }^{1 *}$ \\ ${ }^{1}$ Faculty of Engineering and Applied Science, University of Ontario Institute of Technology, Oshawa, CANADA \\ *Corresponding Author: marc.rosen@uoit.ca \\ Citation: Rosen, M. A. (2018). One Year of Sustainable Development Research. European Journal of \\ Sustainable Development Research, 2(1), 01. https://doi.org/10.20897/ejosdr/82777
}

Published: January 30, 2018

\begin{abstract}
This issue of the European Journal of Sustainable Development Research marks its first anniversary, and demonstrates that the journal has already made a notable impact on the field of sustainable development through having published research on many recent advances. The topics likely to be addressed in the future, and thus covered in the European Journal of Sustainable Development Research, are likely to revolve around the 17 Sustainable Development Goals of the 2030 Agenda for Sustainable Development.
\end{abstract}

Keywords: sustainable development, sustainable development goals, economic sustainability, environmental sustainability, social sustainability

With the release of this issue of the European Journal of Sustainable Development Research, we celebrate the journal's first anniversary. I feel that the journal has gotten off to a very good start, attracting submissions from many fields and countries, reflecting the widespread interest and research activity in sustainable development.

The launch of the journal was auspicious, as it coincided with the launch in many countries of activities to support the 17 Sustainable Development Goals of the 2030 Agenda for Sustainable Development that was adopted by the United Nations in September 2015. These activities include efforts to combat poverty, inequalities, climate change and lack of education. Regarding the latter point, in particular, the European Journal of Sustainable Development Research is already having an impact, making a wide range of research results available for interested parties, thereby enhancing access to knowledge and facilitating new advances and developments. The journal is rapidly becoming a high quality periodical covering numerous areas of sustainable development.

Researchers and journals like the European Journal of Sustainable Development Research play an important role in efforts to address global sustainability challenges, be they technical, economic social or environmental. Given that sustainability is a young field, much research and development remains needed in the many areas of sustainability for the field to grow. For example, practical, meaningful and sound sustainability measures are required that are holistic, while sharing of knowledge, experiences and practices regarding sustainability applications is necessary. The cooperation of sustainable development researchers from technical, environmental, socioeconomic and other backgrounds is essential to advancing sustainable development technologies and approaches. Journals like the European Journal of Sustainable Development Research have an important role to play in this activity, through supporting efforts to address sustainability challenges by providing a productive venue for sharing globally relevant and new knowledge on sustainability.

In its quest for a sustainable option, society faces many challenges in a variety of fields, such as addressing environmental challenges (e.g., climate change), economic issues (e.g., disparities in wealth), and social issues (e.g., low living standards and health care). Some sustainability challenges require technological solutions while others will require economic, political and social ones. Additionally, some challenges, given their multidisciplinary characters, require the cooperation of experts from all these fields and others. One area likely to garner much 
attention, for instance, is energy sustainability. Impressive advances and progress have recently been reported in the field of energy, leading to new generations of renewable energy technologies (e.g., solar, wind, geothermal, biomass), low- or zero-energy buildings, and cleaner automobiles. The consequent improved prospects for renewable energy will facilitate shifts in most societies away from fossil fuels and towards less environmentally intrusive forms of energy. But many challenges to energy sustainability remain, nonetheless.

The topics likely to be addressed in the future, and thus covered in the European Journal of Sustainable Development Research, are likely to revolve around the 17 Sustainable Development Goals of the 2030 Agenda for Sustainable Development. Those goals are wide ranging and comprehensive, likely reflecting heavy areas of activity for the next decade or two. If successful, these efforts should help humanity shift towards sustainability. And the European Journal of Sustainable Development Research will likely have an increasingly important role in making sustainable development research advance advantageously. 